\title{
Mechanistic Understanding of Halogen- mediated Catalytic Processes for Selective Natural Gas Functionalization
}

\author{
Guido Zichittella§, Vladimir Paunović, and Javier Pérez-Ramírez* \\ §SCS-DSM Award for best poster presentation in Catalysis Science and Engineering
}

\begin{abstract}
Development of catalytic technologies enabling the direct functionalization of light alkanes, main components of abundant natural gas, into value-added chemicals and liquid fuels is quite possibly the key strategy to transit from the oil to the renewables era. A cornerstone to meet this great challenge comprises the in-depth understanding of complex reaction mechanisms over dynamic surfaces, allowing to elucidate catalyst design criteria for selective alkane functionalization processes. Prominent examples are the oxybromination of methane into bromomethanes $\left(\mathrm{CH}_{3} \mathrm{Br}+\mathrm{CH}_{2} \mathrm{Br}_{2}\right)$ and the oxychlorination of ethane into ethylene, which are the two highly selective routes (selectivity $\leq 98.5 \%$ ) that have been proposed to involve gas-phase pathways or purely surfacedriven reactions, respectively. Herein, we review our recent efforts to uncover these complex reaction schemes that combine kinetic analysis with advanced operando characterization techniques, including prompt-gamma activation analysis and photoelectron photoion coincidence spectroscopy, ultimately rationalized by density functional theory calculations. In particular, alkane activation to methyl bromide in oxybromination was found to occur in the gas-phase with evolved bromine and bromine radical species, thus enabling to decouple the formation of highly reactive methane-derived intermediates from the catalyst surface that are prone towards combustion. In contrast, the selectivity control in ethane oxychlorination is achieved via a purely surface-driven functionalization of ethane into ethyl chloride, which is further dehydrochlorinated to ethylene over chlorine modified active centers.
\end{abstract}

Keywords: Halogen-mediated selective alkane functionalization · Heterogeneous catalysis - Natural gas . Operando spectroscopy · Reaction mechanism

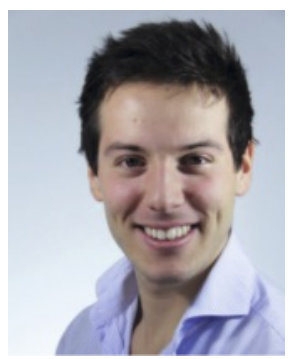

Guido Zichittella is a PhD student in the group of Prof. Pérez-Ramírez. His research focuses on the development of heterogeneous catalysts for the selective activation of light alkanes such as methane, ethane, and propane, via oxyhalogenation chemistry.

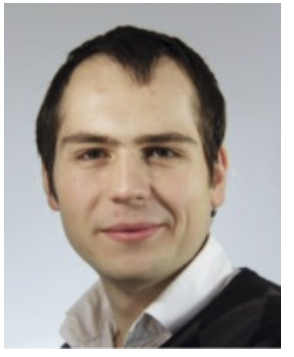

Dr. Vladimir Paunovic is a post-doctoral fellow in the group of Advanced Catalysis Engineering at ETH Zurich. His research centers on developing halogen-mediated processes for natural gas valorization.

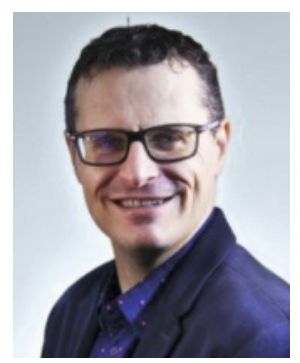

Prof. Javier Pérez-Ramírez holds the Chair of Catalysis Engineering at ETH Zurich. His research pursues the design of heterogeneous catalysts and reactor concepts devoted to sustainable technologies.

\section{Introduction}

Natural gas, mainly composed of light alkanes such as methane $\left(\mathrm{CH}_{4} ; 75-99 \mathrm{~mol} . \%\right)$ and ethane $\left(\mathrm{C}_{2} \mathrm{H}_{6} ; 1-15 \mathrm{~mol} \%\right)$, is regarded as the key feedstock to sustain the manufacture of value-added chemicals and liquid fuels until fully renewable production routes are technically and economically competitive. ${ }^{[1]}$ However, the need for centralized megaplants for commercial harvesting of this resource, in combination with the scattered distribution of a significant fraction (30-60\%) of the gas wells and the high transportation costs, limits the use of natural gas as a chemical feedstock and often results in environmentally harmful flaring and venting practices. ${ }^{[1,2]}$ Accordingly, there has been a great interest in developing catalytic processes aimed at the direct conversion of light alkanes into valuable chemicals that are amenable to decentralization. ${ }^{[3]}$ Alkane functionalization by halogens, such as chlorine or bromine, holds great potential to 
accomplish this goal, since they enable to selectively convert these valuable hydrocarbons at moderate temperatures $(<833 \mathrm{~K})$ and near ambient pressure into alkyl halides, important building blocks from which chemicals and fuels can be obtained via hydrogen halide ( $\mathrm{HX}, \mathrm{X}=\mathrm{Cl}, \mathrm{Br}$ ) elimination. [1e] Still, the halogenation and alkyl halide upgrading steps release HX in stoichiometric amounts, which needs to be fully recycled in order for any halogen-based process to be feasible. From this perspective, oxyhalogenation, entailing the reaction of alkanes, such as methane and ethane, with $\mathrm{O}_{2}$ and $\mathrm{HX}$, is a highly attractive approach to foster process efficiency, as it enables the byproduct HX to be recovered and these hydrocarbons to be functionalized in one step. ${ }^{[4]}$ Nevertheless, minimizing combustion is the great challenge for the application of this route, which can be tackled by catalyst design. A prominent example is the oxybromination of methane, in which the formation of carbon oxides $\left(\mathrm{CO}_{x}\right)$ can be curbed by precisely tuning the oxidizing potential of the catalyst, ultimately enabling high selectivity $(\leq 98.5 \%)$ to bromomethanes $\left(\mathrm{CH}_{3} \mathrm{Br}+\mathrm{CH}_{2} \mathrm{Br}_{2}\right)$ at relevant methane conversion ( $\mathrm{ca}$. $20 \%$ ) (Fig. 1a). ${ }^{[4 a-e]}$ Similarly, the oxychlorination of ethane was recently shown to selectively $(\geq 95 \%)$ generate ethylene $\left(\mathrm{C}_{2} \mathrm{H}_{4}\right)$ over several systems, such as vanadium phosphate $\left((\mathrm{VO})_{2} \mathrm{P}_{2} \mathrm{O}_{7}\right)$, titania $\left(\mathrm{TiO}_{2}\right)$, and especially iron phosphate $\left(\mathrm{FePO}_{4}\right)$, and europium oxychloride $(\mathrm{EuOCl})$ at virtually any degree of ethane conversion. Strikingly, ethylene yields as high as $90 \%$ were achieved over the latter catalyst, thus surpassing any existing olefin production technology (Fig. 1b). ${ }^{[4 g]}$

In this article, we will review our recent efforts that enabled to unravel the mechanistic origin of such selectivity control in the functionalization of methane and ethane via oxyhalogenation. In particular, we combined kinetic analysis with advanced operando characterization techniques, including prompt-gamma activation analysis (PGAA) and photoelectron photoion coincidence (PEPICO) spectroscopy, ultimately rationalized by density functional theory (DFT) calculations, in order to obtain a detailed mechanistic picture of a complex reaction network.

\section{Kinetic Analysis of Alkane Oxyhalogenation}

Several catalytic systems, including ruthenia $\left(\mathrm{RuO}_{2}\right)$, ceria $\left(\mathrm{CeO}_{2}\right),(\mathrm{VO})_{2} \mathrm{P}_{2} \mathrm{O}_{7}, \mathrm{FePO}_{4}$, magnesia-supported ceria $\left(\mathrm{CeO}_{2} /\right.$ $\mathrm{MgO})$, silica-supported palladium $\left(\mathrm{Pd} / \mathrm{SiO}_{2}\right)$, and europium oxybromide $(\mathrm{EuOBr})$, have been investigated in methane oxybromination under comparable reaction conditions..$^{[4 a-e]}$ These materials showed distinct oxidizing potential, decreasing in the order $\mathrm{RuO}_{2}$ $>\mathrm{CeO}_{2}>$ (VO) $)_{2} \mathrm{P}_{2} \mathrm{O}_{7}>\mathrm{FePO}_{4}>\mathrm{CeO}_{2} / \mathrm{MgO}>\mathrm{Pd} / \mathrm{SiO}_{2}>\mathrm{EuOBr}$, which correlated to a diminished formation of $\mathrm{CO}_{x}$ and a concomitant increase in the production of bromomethanes (Fig. 1a). Still, even if combustion reactions are suppressed, the selectivity to methyl bromide $\left(\mathrm{CH}_{3} \mathrm{Br}\right)$ remains limited by the inevitable formation of dibromomethane $\left(\mathrm{CH}_{2} \mathrm{Br}_{2}\right)$, as observed over any investigated system (Fig. 1a). ${ }^{[4 a-f, 5]}$ Notably, kinetic analysis over these catalysts in methane oxybromination showed that bromine $\left(\mathrm{Br}_{2}\right)$ is formed at the reactor outlet, whereby the increase of the reaction temperature reduces its yield and favors the production of bromomethanes. ${ }^{[4 a, b, f]}$ In addition, methane oxybromination was found to occur in the same temperature region of free-radical methane bromination, while both reactions showed similar activation energy and $\mathrm{CH}_{4}$ partial reaction order. ${ }^{[4 \mathrm{~b}, \mathrm{f}]}$ This led to the hypothesis that methyl bromide might be formed in the gas-phase via in situ generated $\mathrm{Br}_{2}$, thus explaining the limited selectivity to methyl halide that is characteristic of free-radical halogenation. In order to assess the impact of the halogen source, methane oxychlorination was also investigated over the same systems, which was found to generally obtain lower selectivities $(<90 \%)$ to chloromethanes $\left(\mathrm{CH}_{3} \mathrm{Cl}+\mathrm{CH}_{2} \mathrm{Cl}_{2}\right)$ compared to methane oxybromination at $\mathrm{ca}$. $20 \% \mathrm{CH}_{4}$ conversion. ${ }^{[4 \mathrm{~b}, \mathrm{e}]}$ Additionally, kinetic analysis demonstrated that the oxychlorination performance correlated with the
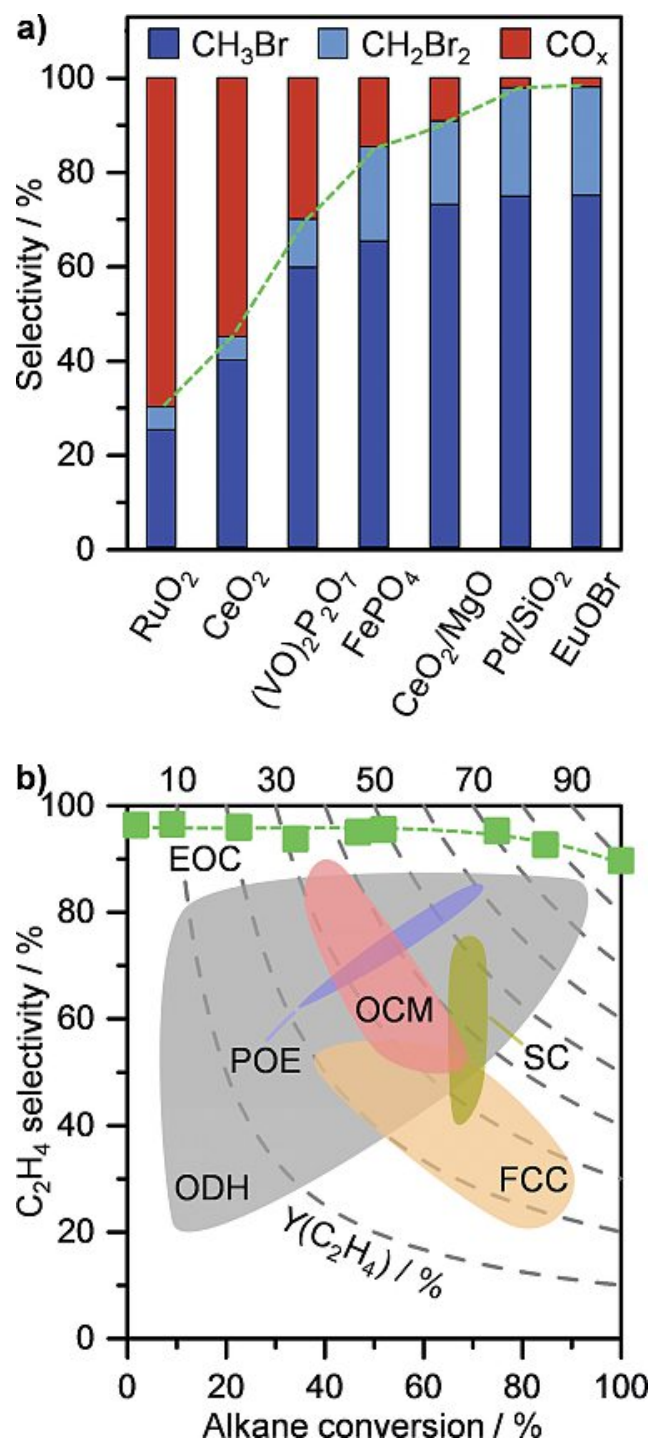

Fig. 1. a) Selectivity to products in methane oxybromination over several catalyst families, determined at ca. $20 \%$ conversion of methane. The combined selectivity to bromomethanes $\left(\mathrm{CH}_{3} \mathrm{Br}+\mathrm{CH}_{2} \mathrm{Br}_{2}\right)$ can be tuned by adjusting the oxidizing potential of the catalyst, which decreases from left to right. ${ }^{[4 b-e]}$ b) Selectivity to ethylene as a function of alkane conversion in the oxychlorination of ethane (EOC) over EuOCl. The dashed gray lines indicate the olefin yield, whereas the colored areas denote the alkane conversion and olefin selectivity achievable in the oxidative dehydrogenation (ODH; gray) and partial oxidation of ethane (POE; blue), oxidative coupling of methane (OCM; red), as well as fluid catalytic cracking (FCC; orange) and steam cracking (SC; olive green) of ethane and naphtha. ${ }^{[4 \mathrm{~g}]}$ All results are expressed on a molar basis.

catalyst ability to produce molecular chlorine $\left(\mathrm{Cl}_{2}\right)$ over virtually any material investigated. ${ }^{[4 b, e]}$ Similar to methane oxybromination, this lead to the hypothesis that this reaction might also involve gas-phase contributions.

Analogously to the work on methane oxyhalogenation, kinetic analysis was conducted in ethane oxychlorination over several systems..$^{[4-i]}$ It was found that the catalysts exhibiting high selectivity to $\mathrm{C}_{2} \mathrm{H}_{4}$, including the best performing $\mathrm{EuOCl}$ and $\mathrm{FePO}_{4}$, were unable to produce $\mathrm{Cl}_{2}$ under typical oxychlorination conditions, while they exhibited very high activity in the dehydrochlorination of ethyl chloride into $\mathrm{C}_{2} \mathrm{H}_{4}$. Consequently, it was proposed that this reaction involves the surface-catalyzed activation of ethane into ethyl chloride that is selectively dehydrochlorinated into ethylene. Furthermore, the influence of the halide was assessed in ethane oxyhalogenation over several catalysts, including europium oxyhalides and $\mathrm{FePO}_{4} \cdot{ }^{[4 \mathrm{~h}, \mathrm{i}]}$ Kinetic analysis in ethane oxybromination revealed stark differences in 
the product distribution compared to oxychlorination under similar conditions (vide infra Fig. 5, center). In particular, ethyl bromide was the main product in oxybromination, especially at low ethane conversion $(\leq 10 \%)$. At higher conversion levels $(\geq 20 \%)$, $\mathrm{C}_{2} \mathrm{H}_{4}$ was also produced, although the selectivity was generally limited $(\leq 60 \%)$ due to the formation of cracking and combustion products. Moreover, these catalysts were able to oxidize $\mathrm{HBr}$ into $\mathrm{Br}_{2}$, which can react with ethane in the gas phase under the same conditions of ethane oxybromination. It was therefore put forward that ethane functionalization in oxybromination occurs in the gas phase in a similar mechanism of methane activation in oxyhalogenation. ${ }^{[4 \mathrm{~h}, \mathrm{i}]}$

To understand the mechanistic origin of the selectivity control in ethane oxychlorination and methane oxybromination compared to the respective counterpart reactions, a strategy that complements kinetic analysis with advanced characterization techniques, which are able to experimentally probe the gas-phase as well as the catalyst surface during reaction conditions, and ultimately rationalized by DFT calculations, is necessary.

\section{Quantifying Surface Chemistry in Alkane Functionalization}

Operando PGAA, which was conducted at the Budapest Neutron Center, was applied in order to quantify adsorbed halogen species on the catalyst surface, here referred to as halogen uptake, during the reaction. ${ }^{[6]}$ This technique has been proven very valuable by our group to understand the halogen dynamics over catalytic surfaces in HX oxidation, an alternative route for halogen recovery. ${ }^{[1 \mathrm{e}]}$ In this characterization technique, a continuous-flow fixed-bed reactor in which the reaction is occurring, is irradiated by a flux of cold prompt neutrons that allows non-destructive element identification and quantification, as schematized in Fig. 2. Consequently, the nuclei of all atoms in the volume of interest are excited, and in order to return to a status of low energy, they emit prompt-gamma rays with energies that are element specific and intensities proportional to the number of emitting atoms. ${ }^{[7]}$

This technique was applied to study ethane oxychlorination and oxybromination over $\mathrm{FePO}_{4}$ and methane oxybromination over $(\mathrm{VO})_{2} \mathrm{P}_{2} \mathrm{O}_{7^{\circ}}[4 \mathrm{f}, \mathrm{i}]$ These two catalysts were chosen as suitable candidates due to their moderate neutron-capture cross-section, contrary to europium-based systems. In particular, at relevant reaction temperatures (723-813 K), the chlorine uptake in ethane oxychlorination was found to vary from $c a .4 .1$ to $3 \mathrm{mmol}_{\mathrm{Cl}} \mathrm{mol}_{\mathrm{Fe}}{ }^{-1}$, equivalent to $76 \%$ and $55 \%$ surface iron sites occupied by chlorine, respectively, and was further correlated to the yield of $\mathrm{C}_{2} \mathrm{H}_{4} \cdot{ }^{[4 i]}$ On the other hand, in the oxybromination of methane and ethane over both phosphate catalysts, the bromine uptake remained statistically insignificant at relevant conditions. ${ }^{[4 f, i]}$ Consequently, the vitrtual absence of bromine on the catalyst surface during the reaction suggests that the latter can evolve into gaseous bromine species, which can react with the alkane in the gas-phase.

\section{Unraveling Gas-phase Pathways in Alkane Activation}

In order to gain experimental evidence that gas-phase pathways are significant in methane oxychlorination and alkane oxybromination, the detection of highly reactive intermediates as radicals is required. To achieve this goal, we have applied operando
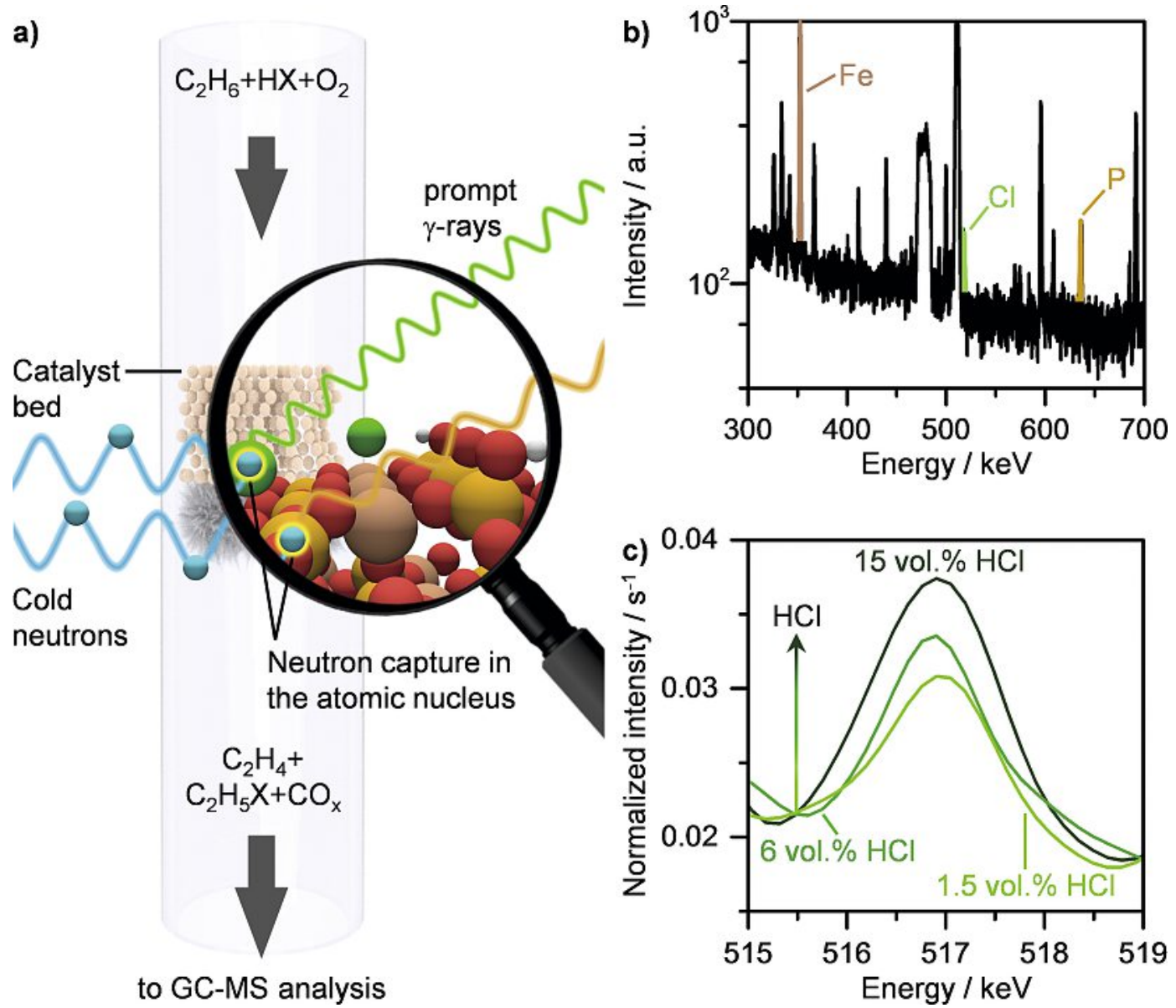

Fig. 2. a) Schematic representation of operando prompt gamma activation analysis, exemplified during ethane oxyhalogenation, in a continuous-flow tubular reactor, where the catalyst, e.g. FePO , is irradiated by a flux of non-destructive cold prompt neutrons, targeting the nuclei of all atoms in the volume of interest. Prompt gamma rays are thus emitted with energies that are element-specific and intensities that are proportional to the number of emitting atoms, as exemplified by b) the PGAA spectrum at standard concentration $\left(\mathrm{C}_{2} \mathrm{H}_{6}: \mathrm{HCl}_{2}: \mathrm{O}_{2}: \mathrm{Ar}: \mathrm{He}_{=} 6: 6: 3: 4.5: 80.5\right)$ and c) the time-normalized $\mathrm{PGAA}$ response at varying $\mathrm{HCl}$ inlet concentration during ethane oxychlorination at $813 \mathrm{~K} .{ }^{[4]}$ 
PEPICO spectroscopy in these reactions, which was performed using the PEPICO endstation at the vacuum ultraviolet (VUV) beamline of the Swiss Light Source at the Paul Scherrer Institute. ${ }^{[8]}$ The particular configuration of the PEPICO micro-reactor and of the gas-phase sampling set-up, as schematized in Fig. 3, enables to minimize the quenching of the short-lived reaction intermediates that are desorbed from the catalyst surface or generated in the gas-phase above the catalyst by high dilution of the feed and low pressure inside the reactor $(\mathrm{ca} .1-4 \mathrm{kPa})$ and the source chamber surrounding its outlet (ca. $2 \mathrm{mPa}){ }^{[4 \mathrm{ff}, 9]}$ The effluent reactor stream forms a molecular beam, which is skimmed and ionized by monochromatic VUV radiation, yielding photoelectrons and photoions that are accelerated by a constant electric field in opposite directions and are detected in delayed coincidence. ${ }^{\left[{ }^{8]}\right.}$ The first detector distinguishes the photoions based on their time of flight, which is correlated to their mass to charge $(m: z)$ ratio, thus indicating the identity of the species (Fig. 3, top). The latter could originate from direct photoionization, i.e. as species related to the reaction, or from dissociative photoionization, entailing molecular dissociation induced by high photon energy $(h v)$, e.g. $\mathrm{CH}_{3} \mathrm{Br}+h v \rightarrow \mathrm{CH}_{3}^{+}$ $+\mathrm{Br}+\mathrm{e}^{-}$, and therefore both yielding photoions of the same $m: z$. In order to distinguish them, the photon energies of each experiment are selected so that they are above the neutral ionization energy of the targeted species, thus allowing direct photoionization, but below its dissociative photoionization threshold. This approach suppresses molecular fragmentation quantitatively and ensures that the detected ions stem exclusively from the photoionization of the neutral or radical species with the same $m: z \cdot{ }^{[4 e]}$ For instance, in order to relate the detection of methyl ions $\left(\mathrm{CH}_{3}^{+}\right)$to the photoionization of methyl radicals $\left(\mathrm{CH}_{3}{ }^{-}\right)$, the photon energy at which the spectra of $\mathrm{CH}_{3}^{+}$were recorded in the methane oxybromination experiments, i.e. $10.0 \mathrm{eV}$, sits well below the threshold for dissociative photoionization of $\mathrm{CH}_{4}(14.3 \mathrm{eV})$ and $\mathrm{CH}_{3} \mathrm{Br}(12.8 \mathrm{eV})$ that could potentially yield ions at $m: z=15$ upon exposure to VUV radiation. ${ }^{[4 \mathrm{e}, \mathrm{f}]}$ Furthermore, additional information on the origins of the photoions stem from the detected photoelectrons. In particular, the mass-selected threshold photoelectron spectra (ms-TPES) indicates the exact energy of photoionization, while its profile represents a characteristic of the given species. In the case of $\mathrm{CH}_{3}^{+}$, the ms-TPES, as exemplified in the bottom panel of Fig. 3, shows a peak at $9.84 \mathrm{eV}$, which is the literature reported value for the ionization of $\left.\mathrm{CH}_{3} \cdot{ }^{[}{ }^{[4]}\right]$ The VUV photon energies used for the detection of the ions of bromine $\left(\mathrm{Br}^{+}\right)$, chlorine $\left(\mathrm{Cl}^{+}\right)$, and ethyl $\left(\mathrm{C}_{2} \mathrm{H}_{5}^{+}\right)$in any other alkane oxyhalogenation experiments were chosen in a similar manner to the example of $\mathrm{CH}_{3}^{+}$.

By conducting operando PEPICO spectroscopy in methane oxybromination over (VO) $\mathrm{P}_{2} \mathrm{O}_{7}, \mathrm{EuOBr}$, and $\mathrm{Pd} / \mathrm{SiO}_{2}$, it was found that this reaction involves the formation of $\mathrm{Br}_{2}$ as well as bromine radicals $\left.(\mathrm{Br})^{\circ}\right)$. Furthermore, generation of ${ }^{2} \mathrm{CH}_{3} \mathrm{Br}$ over these systems was correlated to the formation of $\mathrm{CH}_{3}{ }^{\cdot}$ under several conditions. ${ }^{[4 \mathrm{e}, \mathrm{f}]}$ Similarly, measurements in methane oxychlorination over $\mathrm{Pd} / \mathrm{SiO}_{2}$ also confirmed that this reaction comprises the formation of $\mathrm{Cl}_{2}$ and chlorine radicals $\left(\mathrm{Cl}^{\circ}\right) .{ }^{[4 \mathrm{e}]}$ Still, gas-phase contributions to methane activation were quantified over $\mathrm{Pd} / \mathrm{SiO}_{2}$ to be at least comparable to surface-driven pathways in methane oxychlorination, while in methane oxybromination they were found to contribute for $>90 \%$ to the observed reaction rate. ${ }^{[4 e]}$ The predominance of gas-phase pathways might explain the observed higher combined selectivities to halomethanes in oxybromination compared to oxychlorination, since they enable to decouple the formation of the highly reactive methane-derived intermediates from the catalyst surface, which can be prone towards combustion reactions. Similar to methane oxyhalogenation, operando PEPICO experiments were conducted in ethane oxyhalogenation over $\mathrm{FePO}_{4}$. Interestingly, neither $\mathrm{Cl}_{2}$ nor $\mathrm{Cl}^{-}$were observed in ethane oxychlorination under any investigated conditions, indicating the absence of gas-phase pathways. On the other hand, $\mathrm{Br}_{2}, \mathrm{Br}^{*}$, and
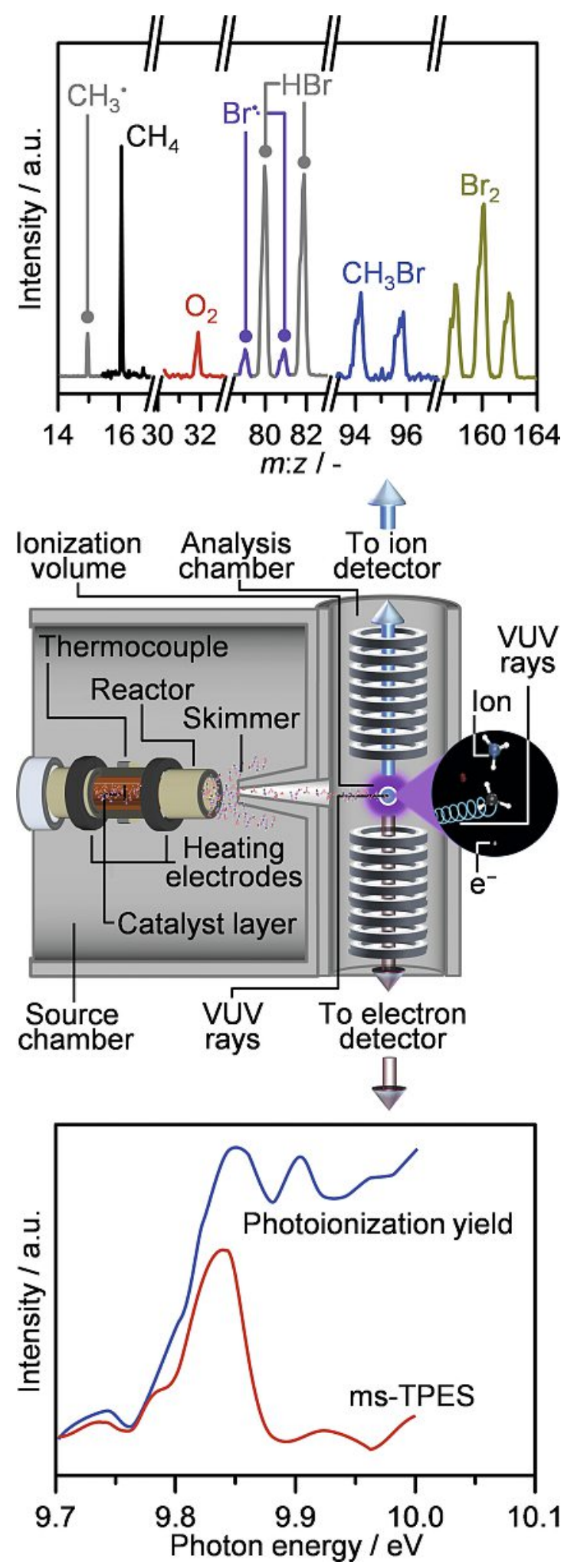

Fig. 3. The central panel illustrates a schematic representation of the PEPICO reactor set-up for radical detection, comprising a resistively heated $\mathrm{SiC}$ reactor on whose inner walls the catalyst, e.g. EuOBr, is deposited. The central part of the molecular beam escaping the reactor is selected by a skimmer and fed to the analysis chamber, wherein it is photoionized by monochromatic vacuum ultraviolet (VUV) synchrotron radiation. The excited molecules are therefore split into photoions and photoelectrons that are accelerated by a constant electric field in opposite directions to the respective detectors. Photoions are distinguished based on their mass to charge ratio $(m: z)$, as shown in the top panel, while the photoelectrons are detected in delayed coincidence and give information on the origin of the former species, as shown in the bottom panel. The latter can originate from direct photoionization or dissociative photoionization events, which can be distinguished by photoelectron analysis, such as the massselected threshold photoelectron spectra (ms-TPES). ${ }^{[4]}$ 
ethyl radicals $\left(\mathrm{C}_{2} \mathrm{H}_{5}{ }^{\circ}\right)$ were identified during ethane oxybromination. In particular, it was observed that the formation of $\mathrm{C}_{2} \mathrm{H}_{5} \cdot$ correlated with the generation of $\mathrm{Br}^{\circ}$ at increasing temperatures, suggesting that ethane activation proceeds via gas-phase chemistry. ${ }^{[4 i]}$

\section{Mechanistic Understanding of Alkane Activation in Catalytic Oxyhalogenation}

In order to rationalize the evidence gathered from kinetics as well as operando PGAA and PEPICO spectroscopies, DFT calculations were conducted in alkane oxyhalogenation. ${ }^{[4 f, i]}$ In particular, (VO) ${ }_{2} \mathrm{P}_{2} \mathrm{O}_{7}$ was used as a model system in methane oxybromination, and it was found that $\mathrm{HBr}$ can dissociatively adsorb on its surface, yielding surface bromine $\left(\mathrm{Br}^{*}\right)$ and a proton. Notably, after adsorption of two $\mathrm{HBr}$ molecules, the elimination of adsorbed $\mathrm{Br}^{*}$ can proceed via two pathways. The first involves the recombination of $\mathrm{Br}^{*}$ to generate $\mathrm{Br}_{2}$, while the second entails the desorption of $\mathrm{Br}^{*}$ in the form of gas-phase $\mathrm{Br}^{*}$, which are barrierless steps at temperatures commonly used in oxybromination (ca. $753 \mathrm{~K}$ ). Once ejected from the catalyst surface, $\mathrm{Br}_{2}$ and $\mathrm{Br}^{\circ}$ can abstract a hydrogen atom from $\mathrm{CH}_{4}$ in the gas phase, leading to the formation of $\mathrm{CH}_{3}$ and $\mathrm{HBr}$, with an energy barrier of $c a$. $1.25 \mathrm{eV}$, i.e. $121 \mathrm{~kJ} \mathrm{~mol}^{-1}$, which is comparable to the experimentally determined apparent activation energy for methane oxybromination and non-catalytic methane bromination. This implies that $\mathrm{C}-\mathrm{H}$ bond scission is the rate-determining step of methane oxybromination, in good agreement with kinetic analyses. The $\mathrm{HBr}$ produced in the methane activation step can regenerate $\mathrm{Br}{ }^{\circ}$ by surface oxidation, while $\mathrm{CH}_{3}{ }^{\circ}$ can react with $\mathrm{Br}_{2}$ forming $\mathrm{CH}_{3} \mathrm{Br}$ and regenerating $\mathrm{Br}^{\circ}$ (Fig. 4). ${ }^{[4 \mathrm{f}]}$ Furthermore, this mechanism rationalizes the observed formation of $\mathrm{CH}_{2} \mathrm{Br}_{2}$ in methane oxybromination over virtually any investigated system, which is a direct consequence of the radical-based methane activation pathway.

In ethane oxyhalogenation, $\mathrm{FePO}_{4}$ was used as a model catalyst for DFT calculations. ${ }^{[4 i]}$ In particular, it was found that in ethane oxychlorination the formation of chlorine in the form of $\mathrm{Cl}_{2}$ or $\mathrm{Cl}^{\circ}$ was strongly limited $(>2.5 \mathrm{eV})$, while the evolution of $\mathrm{Br}_{2}$ and $\mathrm{Br}^{*}$

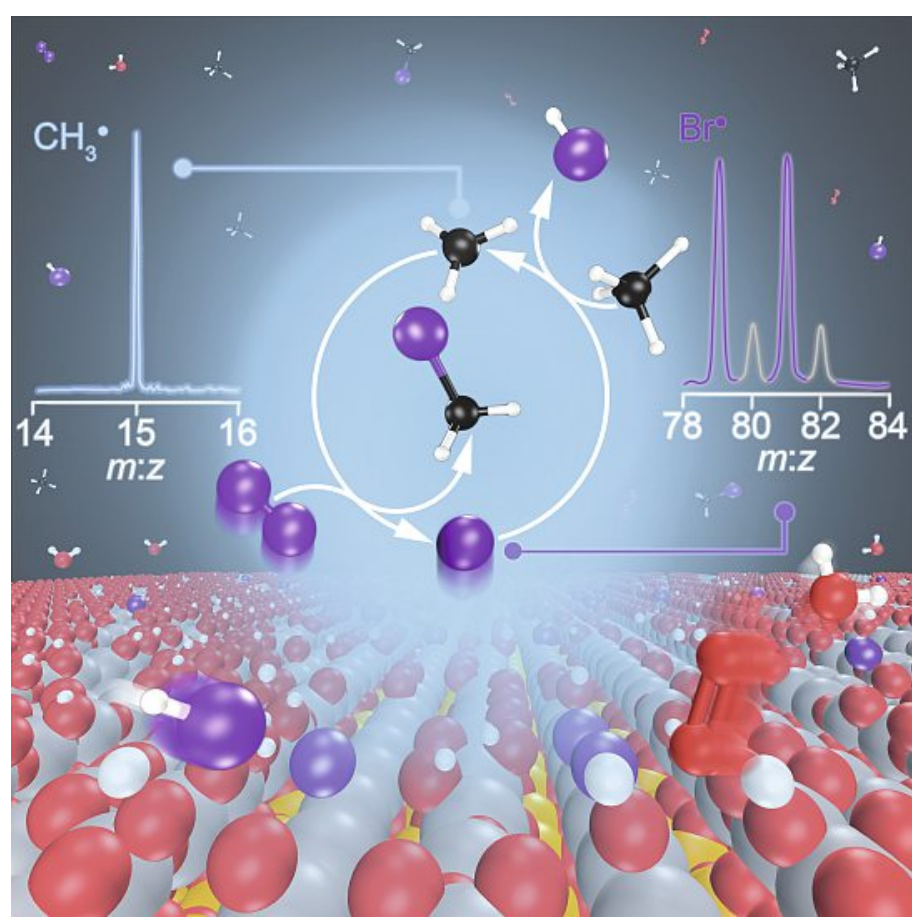

Fig. 4. Representation of the mechanism of methane activation via oxybromination over $(\mathrm{VO})_{2} \mathrm{P}_{2} \mathrm{O}_{7}$, involving the catalytic oxidation of $\mathrm{HBr}$ to $\mathrm{Br}_{2}$ and $\mathrm{Br}$ that, after desorption, react with methane in the gas phase. This detailed mechanistic picture was acquired by combining kinetic analysis with operando PEPICO and PGAA, and ultimately rationalized by DFT calculations. ${ }^{[4]}$ from the catalyst surface in ethane oxybromination was possible $(<2.0 \mathrm{eV})$, in line with results from operando PEPICO. Therefore, in oxychlorination ethane undergoes hydrogen stripping on a $\mathrm{O}-\mathrm{Fe}$ site forming a surface-bound $\mathrm{C}_{2} \mathrm{H}_{5}{ }_{5}$, to which adsorbed chlorine is added barrierlessly forming an adsorbed ethyl chloride (Fig. 5, left). On the other hand, the $\mathrm{Br}_{2}$ and $\mathrm{Br}$ react with ethane in the gas-phase, generating $\mathrm{C}_{2} \mathrm{H}_{5} \mathrm{Br}$ in a similar mechanism to methane activation in oxybromination (Fig. 5, right). Once ethyl halide is formed, $\mathrm{C}_{2} \mathrm{H}_{4}$ is generated by a concerted hydrogen and chlorine abstraction from ethyl chloride on a $\mathrm{Cl}-\mathrm{Fe}$ site in oxychlorination, while in oxybromination it occurs in two separated steps over a $\mathrm{O}-\mathrm{Fe}$ center (Fig. 5). The concerted $\mathrm{HCl}$ abstraction mechanism, which is favored by $c a$. $0.5 \mathrm{eV}$ over the two-step counterpart, was found possible due to the much higher halogen uptake in oxychlorination compared to oxybromination as evidenced via operando PGAA. This might explain the comparatively low selectivity to $\mathrm{C}_{2} \mathrm{H}_{4}$ in bromine-mediated ethane activation. Additionally, the halogen-free surface in ethane oxybromination is more prone to favor side cracking and combustion pathways. ${ }^{[4 i]}$

\section{Conclusions and Outlook}

In this contribution, we have reviewed our recent efforts directed towards the molecular level understanding of selective alkane functionalization via halogen-mediated processes. In particular, we have shown a strategy that allows to unravel a detailed mechanistic picture in a complex reaction network, such as the oxyhalogenation of methane and ethane, by combining kinetic studies with advanced characterization techniques, such as prompt gamma activation analysis and photoelectron photoion coincidence spectroscopy, ultimately rationalized by density functional theory. It was found that gas-phase pathways are dominant in methane chemistry regardless of the halide of choice, and are preferred in order to attain high selectivity towards halomethanes, since they enable to decouple the formation of highly reactive methane-derived intermediates from the catalyst surface, which can be prone towards combustion reactions. On the other hand, we have demonstrated that the selectivity control in oxychlorination is achieved via a purely surface-driven functionalization of ethane into ethyl chloride, which is further dehydrochlorinated to ethylene over a chlorine-modified active center. In contrast, alkane activation to ethyl bromide in oxybromination occurs in the gas-phase with evolved bromine and bromine radical species, thus leaving a halogen-free surface that is more prone to additional cracking and combustion pathways. These results provide guidelines for the design of catalysts that enables selective alkane functionalization via oxyhalogenation. Furthermore, they demonstrate that chlorine-based processes hold great potential for the one-step olefin production from ethane in technical scale, while bromine-based routes are preferred for methane activation.

\section{Author contributions}

The manuscript was written through contributions of all authors. All authors have given approval to the final version of the manuscript.

\section{ORCID}

Guido Zichittella: 0000-0002-7062-8720

Vladimir Paunović: 0000-0001-6630-1672

Javier Pérez-Ramírez: 0000-0002-5805-7355

\section{Notes}

The authors declare no competing financial interest.

\section{Acknowledgements}

This work was supported by ETH research grant (ETH-04 16-1). The authors acknowledge Dr. Patrick Hemberger and Dr. Andras Bodi, from the Paul Scherrer Institute, Dr. László Szentmiklósi, from the Hungarian Academy of Sciences, and Prof. Dr. Núria López, from Institute of 

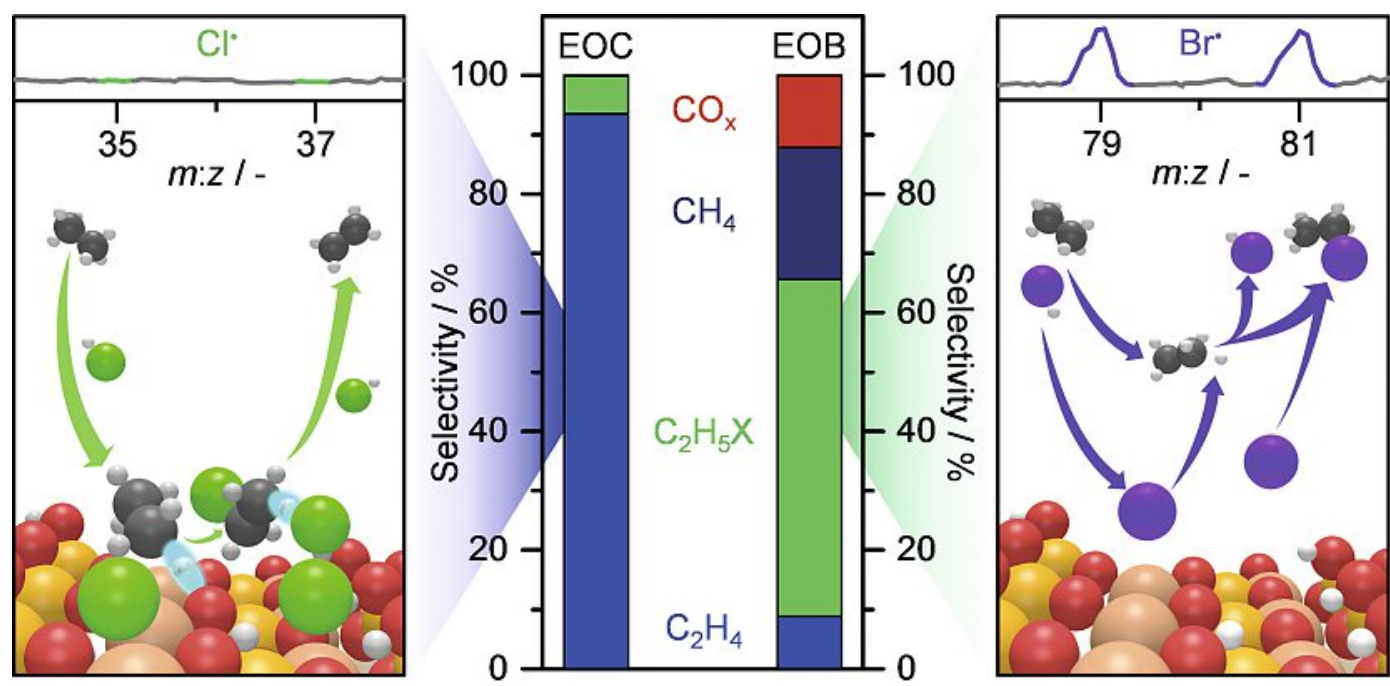

Fig. 5. Selectivity to products in ethane oxyhalogenation over $\mathrm{FePO}_{4}$, determined at ca. $20 \%$ conversion of ethane (middle panel). The observed product distribution originates from the differences in the alkane activation pathway that occurs in the gas-phase with $\mathrm{Br}_{2}$ and $\mathrm{Br}^{\bullet}$ evolving from the catalyst in oxybromination, and exclusively over the catalyst surface in oxychlorination, as illustrated in the right and left panel, respectively. This detailed mechanistic picture was acquired by combining kinetic analysis with operando PEPICO and PGAA, and ultimately rationalized by DFT calculations. ${ }^{[4]}$

Chemical Research of Catalonia, for the long-standing and fruitful collaborations and exciting discussions in this field.

Received: January 28, 2019

[1] a) P. C. Bruijnincx, B. M. Weckhuysen, Angew. Chem. Int. Ed. 2013, 52, 11980; b) R. Horn, R. Schlögl, Catal. Lett. 2015, 145, 23; c) A. I. OlivosSuarez, À. Szécsényi, E. J. M. Hensen, J. Ruiz-Martinez, E. A. Pidko, J. Gascon, ACS Catal. 2016, 6, 2965; d) J. J. Sattler, J. Ruiz-Martinez, E. Santillan-Jimenez, B. M. Weckhuysen, Chem. Rev. 2014, 114, 10613; e) R. Lin, A. P. Amrute, J. Pérez-Ramírez, Chem. Rev. 2017, 117, 4182.

[2] a) C. Hammond, S. Conrad, I. Hermans, ChemSusChem 2012, 5, 1668; b) J. Tollefson, Nature 2016, doi: 10.1038/nature.2016.19141.

[3] a) R. A. Periana, D. J. Taube, S. Gamble, H. Taube, T. Satoh, H. Fujii, Science 1998, 280, 560; b) X. Guo, G. Fang, G. Li, H. Ma, H. Fan, L. Yu, C. Ma, X. Wu, D. Deng, M. Wei, D. Tan, R. Si, S. Zhang, J. Li, L. Sun, Z. Tang, X. Pan, X. Bao, Science 2014, 344, 616; c) S. Grundner, M. A. Markovits, G. Li, M. Tromp, E. A. Pidko, E. J. Hensen, A. Jentys, M. Sanchez-Sanchez, J. A. Lercher, Nat. Commun. 2015, 6, 7546; d) F. Cavani, N. Ballarini, A. Cericola, Catal. Today 2007, 127, 113; e) F. Cavani, Catal. Today 2010, 157, 8; f) C. A. Gärtner, A. C. van Veen, J. A. Lercher, ChemCatChem 2013, 5 , 3196; g) D. A. Goetsch, L. D. Schmidt, Science 1996, 271, 1560; h) A. S. Bodke, D. A. Olschki, L. D. Schmidt, E. Ranzi, Science 1999, 285, 712.

[4] a) V. Paunović, G. Zichittella, M. Moser, A. P. Amrute, J. Pérez-Ramírez, Nat. Chem. 2016, 8, 803; b) G. Zichittella, V. Paunović, A. P Amrute, J. Pérez-Ramírez, ACS Catal. 2017, 7, 1805; c) V. Paunović, R. Lin, M.
Scharfe, A. P. Amrute, S. Mitchell, R. Hauert, J. Pérez-Ramírez, Angew. Chem. Int. Ed. 2017, 56, 9791; d) V. Paunović, G. Zichittella, S. Mitchell, R. Hauert, J. Pérez-Ramírez, ACS Catal. 2018, 8, 291; e) V. Paunović, G. Zichittella, P. Hemberger, A. Bodi, J. Pérez-Ramírez, ACS Catal. 2019, doi: 10.1021/acscatal.8b04375; f) V. Paunović, P. Hemberger, A. Bodi, N. López, J. Pérez-Ramírez, Nat. Catal. 2018, 1, 363; g) G. Zichittella, N. Aellen, V. Paunović, A. P. Amrute, J. Pérez-Ramírez, Angew. Chem. Int. Ed. 2017, 56, 13670; h) G. Zichittella, B. Puértolas, V. Paunović, T. Block, R. Pöttgen, J. Pérez-Ramírez, Catal. Sci. Technol. 2018, 8, 2231; i) G. Zichittella, M. Scharfe, B. Puértolas, V. Paunović, P. Hemberger, A. Bodi, L. Szentmiklósi, N. López, J. Pérez-Ramírez, Angew. Chem. Int. Ed. 2019, doi: 10.1002/ anie.201811669.

[5] a) G. Zichittella, B. Puértolas, S. Siol, V. Paunović, S. Mitchell, J. PérezRamírez, ChemCatChem 2018, 10, 1282; b) V. Paunović, M. Artusi, R. Verel, F. Krumeich, R. Hauert, J. Pérez-Ramírez, J. Catal. 2018, 363, 69.

[6] a) G. L. Molnár, 'Handbook of Prompt Gamma Activation Analysis', Springer, 2004; b) L. Szentmiklósi, T. Belgya, Z. Révay, Z. Kis, J. Radioanal. Nucl. Chem. 2010, 286, 501.

[7] a) Z. Revay, Anal. Chem. 2009, 81, 6851; b) L. Szentmiklósi, J. Radioanal. Nucl. Chem. 2017, 315, 663 .

[8] a) A. Bodi, M. Johnson, T. Gerber, Z. Gengeliczki, B. Sztaray, T. Baer, Rev. Sci. Instrum. 2009, 80, 1; b) B. Sztáray, K. Voronova, K. G. Torma, K. J. Covert, A. Bodi, P. Hemberger, T. Gerber, D. L. Osborn, J. Chem. Phys. 2017, 147,1 .

[9] Q. Guan, K. N. Urness, T. K. Ormond, D. E. David, G. Barney Ellison, J. W. Daily, Int. Rev. Phys. Chem. 2014, 33, 447. 